\title{
ANÁLISE DE AÇÕES DE PREVENÇÃO E COMBATE AOS INCÊNDIOS FLORESTAIS EM UNIDADES DE CONSERVAÇÃO DO CERRADO
}

\author{
Cláudio Augusto Pereira ${ }^{1}$ \\ Nilton César Fiedler ${ }^{2}$ \\ Marcelo Brilhante de Medeiros ${ }^{3}$
}

\begin{abstract}
RESUMO
A pesquisa teve como objetivo avaliar a eficácia das ações de prevenção e combate aos incêndios florestais nas unidades de conservação do cerrado. Os dados desta pesquisa foram coletados no Parque Nacional da Chapada dos Veadeiros (GO), Parque Nacional das Emas (GO), Parque Nacional de Brasília (DF), Parque Nacional da Chapada dos Guimarães (MT) e Parque Nacional da Serra da Canastra (MG). Para coleta de dados foi desenvolvido um questionário e aplicado aos membros das brigadas e coordenadores das atividades na Unidade de Conservação. Foi também avaliada a infra-estrutura em prevenção e combate. Ao todo foram entrevistados 124 funcionários. Verificou-se que nos Parques há uma elevada carência de maquinas, torres de observação, locais de captação de água e Equipamentos de Proteção Individual. As maiores dificuldades de trabalho salientadas pelos brigadistas foram a carência de infra-estrutura, o patrulhamento insuficiente, ausência de apoio das populações circunvizinhas e os freqüentes atrasos no inicio das atividades de prevenção. $O$ investimento realizado nos últimos anos na contratação de brigadistas e aquisição de material de combate ainda não reduziu a área queimada nos Parques Nacionais. Ainda existem diversos problemas organizacionais e uma grande carência de equipamentos, pessoal e investimento em atividades preventivas.

Palavras-chave: Parques Nacionais, controle de incêndios, combate a incêndios florestais.
\end{abstract}

\section{ANALYSIS OF PREVENTION AND FIGHT ACTIONS RELATED TO FOREST FIRES AT PROTECTED AREAS OF CERRADO}

\begin{abstract}
This research aimed to evaluate the efficiency of actions due to the prevention and fight against the forest fires at Protected Areas of Cerrado. The data were collected at the Chapada dos Veadeiros National Park and Emas National Park, in the state of Goias; Brasilia National Park in the Distrito Federal; Chapada dos Guimarães National Park in the state of Mato Grosso and Serra da Canastra National Park in the state of Minas Gerais. These states are all in Brazil. It was developed a questionnaire according to the data collected, applied to members of firefights and activities coordinators at Conservation Unities. It was also evaluated the infrastructure in prevention and fight. At all, 124 workers were interviewed. In most of the the Parks were verified that there was a high lack of machines, observation towers and strategic places for water and individual protection equipment capitation. The greatest work difficulties related by the firefighters were the lack of infrastructure, insufficient vigilance, little help from the neighbour population and frequent lateness in the beginning of prevention activities. The investment made in the latest years for firefighters admission and the acquisition of combat materials did not reduced the number of fires at the Parks. There are still many problems related to organization and a huge necessity of equipment, people and investments in preventive activities.
\end{abstract}

Key-Words: National Parks; fire control; forest firefights.

\section{INTRODUÇÃO}

Anualmente os incêndios florestais atingem grandes áreas nas Unidades de Conservação brasileiras (IBAMA, 2002).

Esses incêndios podem provocar prejuízos importantes, tanto humanos (perda de vidas) como ambientais (recursos hídricos,

solos, qualidade do ar, danos na fauna e na flora), tendo também conseqüências econômicas consideráveis como perdas de estoques de madeira e custos com as atividades de combate. No Brasil, as causas de incêndios em Unidades de Conservação têm sido

\footnotetext{
${ }^{1}$ Bolsista - PIBIC - CNPq - Depto Enga Florestal - UnB. E-mail: claudioap@pop.com.br.

${ }^{2}$ Professor Adjunto -Departamento de Engenharia Florestal - UnB. E-mail: fiedler@unb.br;

${ }^{3}$ Pesquisador EMBRAPA-CENARGEN-Brasília-DF.Email: medeiros@cenargen.embrapa.br

AGRADECIMENTOS: CNPq; PREVFOGO/IBAMA; DIREC/IBAMA; Parque Nacional da Chapada dos Veadeiros; Parque Nacional de Brasília; Parque Nacional da Chapada dos Guimarães; Parque Nacional das Emas e Parque Nacional da Serra da Canastra
} 
principalmente devido ao uso incorreto do fogo para renovação de pastagens e limpeza de restos de cultura nas propriedades vizinhas (Medeiros 2002).

A ocorrência de fogo em áreas de cerrado e outros tipos de vegetação propensos a este distúrbio é considerado natural em determinados regimes. Um regime de fogo "não natural" pode interferir negativamente sobre a biota, modificando os processos evolutivos mantidos sob diferentes condições de fogo (Whelan, 1995).

Os incêndios florestais causam grandes prejuízos à biodiversidade, ao ciclo hidrológico e ao ciclo do carbono na atmosfera. Tais prejuízos reduzem os serviços ambientais que a floresta, mantida em seu padrão atual, poderia proporcionar ao planeta. Uma intensa freqüência de fogo numa mesma região, admitida a hipótese de troca de paisagem, pode levar a perda irreversível de parte de recursos genéticos, antes mesmo de conhecer seu potencial (Silva, 2001).

No Cerrado brasileiro a ocorrência de fogo é um fenômeno muito antigo, o que é evidenciado pela existência de carvão datado entre 27.100 a 41.700 anos antes do presente (AP) (Vicentini, 1993).

O controle dos incêndios florestais depende fundamentalmente de maiores esforços direcionados para a prevenção, ou seja, a atuação nas causas do problema. Os investimentos em combate aos incêndios florestais, embora necessários, devem sempre ser acompanhados de maior empenho em prevenção, sempre se antecipando à época de estiagem com as etapas que podem se iniciar com ações de educação ambiental nas comunidades e rodovias próximas à área protegida.

O combate deve estar voltado para suprimir o incêndio por meio da ação em um ou mais dos componentes do triângulo do fogo, ou seja, combustível, oxigênio e calor (Fiedler et al, 2000).

Os equipamentos de combate aos incêndios florestais devem ser adequados às condições ambientais da área a ser protegida. Estes equipamentos irão sofrer algumas variações em tipo e número, de acordo com o ecossistema considerado (Medeiros, 2001).

O sistema de prevenção e combate a incêndios florestais de uma Unidade de
Conservação requer diversos investimentos em manutenção de aceiros; campanhas educativas de conscientização; sistema de fiscalização; comunicação; ferramentas, máquinas e equipamentos de combate e treinamento de pessoal (Fiedler et al, 2000). No entanto, a eficácia de todo o aparato disponível depende das condições de uso a que são gerenciados nas Unidades de Conservação.

Provavelmente os custos com prevenção são consideravelmente menores que os custos com o combate aos incêndios florestais, sem levar em consideração as enormes perdas sob os diversos aspectos ambientais.

Esta pesquisa teve como objetivo analisar a infra-estrutura em prevenção e combate aos incêndios florestais nas Unidades de Conservação do Cerrado e a eficiência das atividades preventivas realizadas.

\section{MATERIAL E MÉTODOS}

Os dados desta pesquisa foram coletados nas Unidades de Conservação Federais, localizadas no bioma Cerrado, compreendendo o Parque Nacional da Chapada dos Veadeiros e Emas (Goiás), Parque Nacional de Brasília (Distrito Federal), Parque Nacional da Chapada dos Guimarães (Mato Grosso) e Parque Nacional da Serra da Canastra (Minas Gerais).

Os dados foram coletados com a aplicação de um questionário versando sobre técnicas empregadas na prevenção e combate, sua eficácia e possíveis sugestões de modificação e implantação de novas técnicas. Os questionários foram aplicados, em forma de entrevista individualizada aos membros das brigadas e coordenadores das atividades nas Unidades de Conservação.

Foram obtidos junto à administração das Unidades e ao PREVFOGO do IBAMA os dados relativos aos investimentos em prevenção e combate aos incêndios florestais ocorridos nos últimos dez anos (1992 - 2002) e os dados relativos à ocorrência dos incêndios florestais neste período, por meio do relatório de ocorrência de incêndios (ROI). 


\section{RESULTADOS E DISCUSSÃO}

\section{Opiniões dos brigadistas do Parque Nacional da Chapada dos Veadeiros}

Com a análise de dados referente ao questionário aplicado aos bragadistas do Parque Nacional da Chapada dos Veadeiros a quase totalidade $(83 \%)$ dos brigadistas afirmou que são contratados temporariamente, gostam muito do trabalho que desenvolvem na unidade $(100 \%)$, o treinamento foi feito a menos de dois anos com abordagem satisfatória (100\%). Todos os equipamentos de proteção individual (EPI) disponíveis são utilizados (bota, luva, camiseta e calça). Não estavam disponíveis as máscaras, os óculos, o capacete e as caneleiras ou perneiras. Como materiais auxiliares tinham disponíveis o cantil e o rádio receptor, mas faltavam lanternas para o trabalho noturno.

Segundo os brigadistas, todos os EPIs disponíveis eram repostos de maneira adequada, mas a unidade continua carente de máquinas como caminhão pipa, trator, veículos para transporte de brigadistas ou até uma motocicleta e nas horas de extrema urgência um auxílio por meio de um helicóptero.

Não existiam torres de observação instaladas nem alojamento para brigadistas, sendo que ficavam acomodados no alojamento para pesquisadores do Parque.

A visitação pública ao Parque é liberada, com ressalva que é obrigatório o acompanhamento de um guia.

Os maiores problemas ambientais são o fogo $(83 \%)$ e a caça $(66 \%)$. A região em que há maior índice de incêndios é a conhecida como Pouso Alto.

\section{Opiniões dos brigadistas do Parque Nacional de Brasília}

Os brigadistas estavam contratados a aproximadamente três meses e são contratados temporariamente $(100 \%)$, trabalham na prevenção fazendo aceiros( $88 \%$ ), patrulhas $(48 \%)$, conscientização a população do entorno (25\%) e no combate direto( $83 \%)$. Gostam do trabalho que desempenham, mesmo tendo sido feita a escolha do ofício por oportunidade de emprego(75\%).

O treinamento havia sido ministrado também a menos de dois anos (100\%). A abordagem foi satisfatória e as partes teóricas e práticas foram bem divididas. A unidade não possui todos os EPIs. Faltavam as máscaras, capacetes, caneleiras e um uniforme mais resistente ao fogo. Os demais EPIs (luvas, botas , blusa, calça e boné) são usados por todos os brigadistas. Os EPIs são repostos à medida que são danificados, mas a entrega tem sido fragmentada.

Foi constatado que a unidade está bem munida de equipamentos, máquinas $\mathrm{e}$ ferramentas para o combate e prevenção e que há alojamento para os brigadistas, mas segundo $83 \%$ dos entrevistados, não está preparado para pernoite de toda equipe escalada.

Segundo os brigadistas, boa parte dos incêndios é proveniente das regiões da Flona de Brasília (88\%), Lago Oeste (72\%) e lixão da Estrutural (67\%).

\section{Opinião dos brigadistas do Parque Nacional da Serra da Canastra}

A quase totalidade dos brigadistas do Parque Nacional da Serra da Canastra (95\%) afirmou que são contratados temporariamente. Eles gostam muito do trabalho que desenvolvem, pois todos afirmaram que escolheram ser brigadistas pelo interesse com a preservação do Parque (100\%), porém também foram influenciados pela escassez de emprego na região $(100 \%)$.O treinamento foi feito a menos de dois anos com abordagem satisfatória (100\%). Todos os EPIs disponíveis são utilizados (bota, luva, camiseta e calça). Não estavam disponíveis as máscaras, os óculos, as luvas, os capacete e as caneleiras. Os materiais auxiliares disponíveis eram o cantil e rádio receptor comum, mas faltavam lanternas. Todos os EPIs disponíveis eram repostos de maneira adequada.

Existia alojamento para brigadistas, que estava em boas condições (47,5\%). No entanto, a totalidade dos brigadistas salientou que o mesmo deve ser deslocado para um lugar estrategicamente melhor. O Parque não está munido de torres de observação As regiões que há maiores índices de incêndios são conhecidas como Cachoeira Rolinhos, Serra Brava e divisas do Parque.

\section{Opinião dos brigadistas do Parque Nacional da Chapada dos Guimarães}

No Parque Nacional da Chapada dos Guimarães os brigadistas estavam contratados 
a aproximadamente cinco meses e todos foram contratados temporariamente $(100 \%)$. Trabalham na prevenção fazendo aceiros $(100 \%), \quad$ patrulhas $(100 \%)$ e conscientização populacional $(100 \%)$. Todos gostam do trabalho que desenvolvem mesmo tendo sido feito a escolha do ofício por oportunidade de emprego (80\%).

$\mathrm{O}$ treinamento havia sido ministrado a menos de dois anos $(88,3 \%)$. A totalidade salientou que a abordagem foi satisfatória e as partes teóricas e práticas foram bem divididas. Porém, alguns dos brigadistas consideraram que as aulas práticas deveriam ser em número maior $(11,7 \%)$. A Unidade não possuía todos os EPIs. Faltavam máscaras, óculos, capacetes, caneleiras, coturno e um uniforme que resista mais ao fogo. Os EPIs disponíveis (luvas, blusa, calça e boné) eram usados por todos os brigadistas. Os EPIs são repostos a medida que são danificados. Os brigadistas afirmaram que há um pouco de demora por causa da burocracia. Boa parte dos incêndios é proveniente das regiões chamadas Salgadeira (59\%) que é uma área de lazer, rodovias $(41 \%)$, mutuca $(35 \%)$ e fazendas próximas $(23,5 \%)$.

\section{Opinião dos brigadistas do Parque Nacional das Emas}

No Parque Nacional das Emas os brigadistas estavam contratados a aproximadamente seis meses e todos são contratados temporariamente $(100 \%)$. A totalidade trabalha na prevenção fazendo aceiros, patrulhas e conscientização populacional. Foi unânime a opinião de que gostam do trabalho que desenvolvem mesmo tendo sido feito a escolha do ofício por pouca oportunidade de emprego na região. $\mathrm{O}$ treinamento havia sido ministrado também a menos de dois anos. Segundo os brigadistas, a abordagem foi satisfatória e as partes teóricas e práticas foram bem divididas. A unidade não possui todos os EPIs. Faltavam máscaras, óculos, capacetes, caneleiras, coturno e um uniforme mais resistente ao fogo. Os demais EPIs (luvas, blusa, calça e boné) eram usados por todos os brigadistas. Os EPIs são repostos a medida que são danificados, no entanto, salientaram que há um pouco de demora por problemas burocráticos.

Os brigadistas afirmaram que a Unidade está bem munida de equipamentos, máquinas e ferramentas para o combate e prevenção (trator gradeador e caminhão para transporte de brigadistas e tanque "pipa" com capacidade para 10000 litros), porém, não possui torres de observação. Boa parte dos incêndios é proveniente da região chamada Alto da Glória (100\%), mas podem surgir em qualquer lugar, pois há alta incidência de focos provocados por raios $(100 \%)$.

Atividades preventivas desenvolvidas nos Parques Nacionais avaliados

A tabela 1 mostra a opinião dos brigadistas relativas às atividades preventivas desenvolvidas nos Parques Nacionais da Chapada dos Veadeiros, Brasília, Serra da Canastra, Chapada dos Guimarães e Emas. 
Tabela 1: Atividades preventivas desenvolvidas nos Parques Nacionais avaliados

Table 1: Preventives activities developed in National Park evaluated

Trabalho integrado com a brigada

Prática de aceiro com fogo e máquina

Vigilância da unidade

Treinamento e simulação de incêndio

Placas educativas

Palestras aos visitantes

Campanhas nas escolas

Campanhas no entorno da unidade

Queima controlada

$\begin{array}{cc}\text { Parques Nacionais } & \text { Avaliados } \\ \text { Veadeiros } & \text { Brasília } \\ 95 \% & 80 \% \\ 87 \% & 85 \% \\ 82 \% & 77 \% \\ 78 \% & 65 \% \\ 75 \% & 73 \% \\ 72 \% & 65 \% \\ 66 \% & 61 \% \\ 60 \% & 58 \% \\ 43 \% & 68 \%\end{array}$

$\begin{array}{ccc}\text { Canastra } & \text { Guimarães } & \text { Emas } \\ 69 \% & 100 \% & 100 \% \\ 63 \% & 47 \% & 100 \% \\ 53 \% & 41 \% & 100 \% \\ 58 \% & 35 \% & 100 \% \\ 53 \% & 29 \% & 100 \% \\ 53 \% & 29 \% & 100 \% \\ 53 \% & 47 \% & 100 \% \\ 53 \% & 35 \% & 100 \% \\ 53 \% & 29 \% & 100 \%\end{array}$

O Parque Nacional das Emas teve todas as atividades classificadas como excelente. $\mathrm{O}$ trabalho integrado com a brigada teve uma avaliação muito eficiente, com exceção do Parque Nacional da Serra da Canastra que pode ser avaliado como bom. As demais atividades de prevenção foram menos citadas no Parque Nacional da Chapada dos
Guimarães.

Áreas queimadas e protegidas nos Parques Nacionais avaliados

A tabela 2 mostra as áreas queimadas e percentuais protegidos nos Parques Nacionais avaliados entre os anos de 1992 e 2002.

Tabela 2 - Áreas protegidas e queimadas nos Parques Nacionais avaliados

Table 2 - Protected areas and fired in National Park evaluated

\begin{tabular}{|c|c|c|c|c|c|c|c|c|c|c|}
\hline & \multicolumn{2}{|c|}{$\begin{array}{c}\text { Parque Nacional de } \\
\text { Brasília }\end{array}$} & \multicolumn{2}{|c|}{$\begin{array}{l}\text { Parque Nacional da } \\
\text { Serra da Canastra }\end{array}$} & \multicolumn{2}{|c|}{$\begin{array}{l}\text { Parque Nacional das } \\
\text { Emas }\end{array}$} & \multicolumn{2}{|c|}{$\begin{array}{c}\text { Parque Nacional da } \\
\text { Chapada dos Guimarães }\end{array}$} & \multicolumn{2}{|c|}{$\begin{array}{c}\text { Parque Nacional da } \\
\text { Chapada dos Veadeiros }\end{array}$} \\
\hline & $\begin{array}{c}\% \\
\text { protegido }\end{array}$ & $\begin{array}{c}\text { Área } \\
\text { ueimada (hs }\end{array}$ & $\begin{array}{c}\% \\
\text { protegido }\end{array}$ & $\begin{array}{c}\text { Área } \\
\text { ueimada (ha }\end{array}$ & $\begin{array}{l}\% \\
\text { protegido }\end{array}$ & $\begin{array}{c}\text { Área } \\
\text { ueimada (ha) }\end{array}$ & $\begin{array}{c}\% \\
\text { protegido }\end{array}$ & $\begin{array}{l}\text { Área } \\
\text { eimada (ha) }\end{array}$ & $\begin{array}{c}\% \\
\text { protegido }\end{array}$ & $\begin{array}{c}\text { Área } \\
\text { ueimada (ha) }\end{array}$ \\
\hline 1992 & 100,00 & 0,00 & 98,75 & 6500,00 & 63,55 & 48504,00 & 100,00 & 0,00 & 98,73 & 760,00 \\
\hline 1993 & 99,24 & 227,77 & 88,42 & 23156,50 & 100,0 & 0,00 & 100,00 & 0,00 & 87,61 & 7437,00 \\
\hline 1994 & 62,48 & 11256,28 & 83,25 & 33500,00 & 99,90 & 131,87 & 100,00 & 0,00 & 92,62 & 4430,00 \\
\hline 1995 & 82,90 & 5130,01 & 100,00 & 0,00 & 88,73 & 15000,00 & 99,42 & 190,00 & 33,86 & 39682,00 \\
\hline 1996 & 99,94 & 17,00 & 96,25 & 7500,00 & 87,84 & 16175,00 & 100,00 & 0,00 & 100,00 & 0,00 \\
\hline 1997 & 99,93 & 20,30 & 94,44 & 11125,00 & 99,9 & 30,00 & 100, & 0,00 & 100,00 & 0,00 \\
\hline 1998 & 87,27 & 3819,00 & 93,67 & 12660,00 & 99,48 & 690,00 & 100,00 & 0,00 & 68,00 & 19200,00 \\
\hline 1999 & 94,40 & 1678,89 & 99,23 & 1550,00 & 75,61 & 32450,00 & 99,09 & 300,00 & 99,37 & 380,00 \\
\hline 2000 & 99,41 & 177,69 & 89,82 & 20353,00 & 100,00 & 0,00 & 100,00 & 0,00 & 100,00 & 0,00 \\
\hline 2001 & 98,60 & 420,77 & 99,09 & 1820,00 & 89,14 & 14450,00 & 97,42 & 850,00 & 97,67 & 1400,00 \\
\hline 2002 & 99,96 & 13,00 & 77,75 & 44500,00 & 62,82 & 44154,00 & 99,70 & 100,00 & 85,41 & 8757,00 \\
\hline
\end{tabular}

Fonte: Relatório de Ocorrência de Incêndios (ROI) - PREVFOGO / IBAMA.

Apesar da efetivação das brigadas, nos Parques Nacionais a partir do ano 2000, não é possível verificar uma tendência à diminuição das áreas queimadas. Em algumas áreas, como os Parques Nacionais da Serra da Canastra e Chapada dos Veadeiros, grandes áreas continuaram a queimar após o ano 2000.

O Parque Nacional com o maior número de máquinas é o Parque Nacional das Emas, seguido do Parque Nacional da Serra da Canastra. Isso demonstra que a ocorrência do fogo nem sempre está diretamente ligada ao número de equipamentos disponíveis.

\section{CONCLUSÕES}

Segundo a opinião dos brigadistas, verificou-se que nos Parques há uma elevada carência de máquinas, torres de observação, locais de captação de água e EPIs. As maiores dificuldades de trabalho salientadas pelos brigadistas foram a carência de infra-estrutura, o patrulhamento insuficiente, ausência de apoio das populações circunvizinhas e os freqüentes atrasos no início das atividades de prevenção. $\mathrm{O}$ investimento realizado nos últimos anos na contratação de brigadistas e aquisição de material de combate aparentemente não foi suficiente para a 
redução das áreas queimadas. Ainda existem diversos problemas organizacionais e uma grande carência de equipamentos, pessoal e investimento em atividades preventivas.

\section{REFERÊNCIAS}

FIEDLER, N.C.; SILVA, J.C.; SANTIAGO, J.; MEDEIROS, M.B. Combate aos incêndios florestais. In: Revista Comunicações Técnicas Florestais, v.1., n.2. Brasília. 2000. 36 p.

IBAMA. Relatório de Ocorrência de Incêndios Florestais. Documento Técnico. PREVFOGO, (2002). s.p.

MEDEIROS, M. B. Manejo de Fogo em Unidades de Conservação. In: Anais do I Workshop sobre incêndios florestais no Cerrado. Revista Comunicações Técnicas Florestais, v. 3. n.2. Brasília, p. 10-15.
MEDEIROS, M. B. Manejo de Fogo em Unidades de Conservação do Cerrado. Boletim do Herbário Ezechias Paulo Heringer,

SILVA, J.C. Diagnóstico das áreas de maior incidência de incêndios florestais em Unidades de Conservação Pertencentes a APA Gama Cabeça de Veado. Brasília, Universidade de Brasília, Mestrado em Ciências Florestais (Dissertação). 2001.59 p.

VICENTINI, K.R.F.1993. Análise Palinológica de uma vereda em Cromínia-GO. Dissertação de Mestrado.Universidade de Brasília, Brasília, DF.

WHELAN, R. J. The Ecology of Fire. (1995). Cambridge: Cambridge University Press. 